\title{
A Review of Ergonomic Tools and Apparatus for the Ageing Population
}

\author{
Darren Kai Shen Lee ${ }^{1, a}$, Poh Kiat Ng ${ }^{1, b}$, Kian Siong Jee ${ }^{1, c}$, Yue Hang Tan ${ }^{1, d}$ \\ and Mei Ping Leong ${ }^{1, e}$ \\ ${ }^{1}$ Faculty of Engineering and Technology, Multimedia University, Jalan Air Keroh Lama, 75450 \\ Malacca, Malaysia. \\ adarrenlee_1993@hotmail.com, bpkng@mmu.edu.my, 'ksjee@mmu.edu.my, \\ 'tan_hang2003@yahoo.com, ealicemeiping@theiet.org
}

Keywords: Ergonomics, ageing population, garden, kitchen, ergonomic tools, ergonomic apparatus

\begin{abstract}
This paper presents a review of ergonomic garden tools and kitchen apparatus for the ageing population. The purpose of this review is to enable the ageing population to carry out daily activities in the garden and in the kitchen in a less strenuous manner. First, a general review was made on the ergonomic aspect of the garden tool known as Appel Spade. Another review on the ergonomic aspect of the kitchen apparatus was done on the Eggcurate Digital Kitchen Scale. With these reviews, both ergonomic advantages and disadvantages of the Appel Spade and Eggcurate Digital Kitchen Scale are highlighted and then tabulated. Based on the reviews, recommendations are proposed for future potential enhancements in terms of the ergonomic aspects to provide the ageing population a more comfortable experience using these tools and apparatus.
\end{abstract}

\section{Introduction}

As individuals undergo the ageing process, their body and mind experience significant changes. Unsurprisingly, the environment around them changes as well. Population aging is a global phenomenon that carry after effects on numerous attributes of society [1]. Unfortunately, it appears that the elderly are often faced with problems in handling everyday tools and apparatus due in part to the design of these contraptions which fail to consider the limitations of the elderly [2].

Besides the general problems arising in relation to the ageing process, the ageing population is faced with scarce demands when handling consumer products in relation to the sufficiency of energy utilised [3]. The science of ergonomics has the capabilities to improve the design of tools and apparatus such that they become more user-friendly [4]. Tools and apparatus can be remodelled accordingly so that they are easy to use, regardless of the age or physical limitations of the user [5]. This would go a long way to allow older people to do things for themselves and maintain their independence, dignity and sense of self-worth [6].

Gardening has existed since the early days of human civilisation [7]. Kitchens on the other hand, gained its prominence during the post-civil war period [8]. While there has been some research on garden tools and kitchen apparatus involving the working class adults, there appear to be no reviews on these tools involving the ageing population. Therefore, this paper aims to conduct a review of ergonomic tools and apparatus for the ageing population with a special emphasis on garden tools and kitchen apparatus.

\section{Literature Review}

Garden Tools. When you invest in a good ergonomic garden tool, the returns are apparently not just in health aspects but also in ease-of-use and usability. Utilising the right tool for the right job has always been a good call, be it for an occasional gardener or an expert landscaper [9].

When a good ergonomic garden tool is properly utilised, it will reduce the chances of the user to sustain a repetitive stress injury or suffer from an acute trauma whilst gardening [10]. The tool should allow users to work in a suitable posture without excessive twisting, leaning and application of force [10] . This would greatly reduce back and shoulder injuries. Besides that, the tool should allow users to work while keeping a natural wrist position to boost strength and control while avoiding the risk of wrist injury [9]. 
In addition to injury reduction, a good ergonomic garden tool would increase not only the efficiency but also the capacity and performance of the work done [10]. More work can be done in less time and less effort and this helps in easing the strain on the users. In other words, productivity would be improved. Ditch-digging and weed-clearing in the garden would be made much easier using an ergonomic garden tool compared to conventional tools with no ergonomic aspects [9].

The first review will be on the Appel Spade invented by Arie Appel. The Appel Spade as its name suggests, is a spade made completely out of stainless steel and designed in such a way that it is user friendly for gardeners who suffer from arthritis and other disabilities that cause stiffness in the wrists [3].

As shown in Figure 1, unlike any other conventional spade where there is only a single handle, the Appel Spade features two vertical handles connected at the top, forming an inverted U-shape. The space between the footrest and the blade is meant to prevent soil accumulation, a recurring problem in conventional spades. The space between the two vertical handles is devised to permit the knee to be positioned straight above the foot [3].

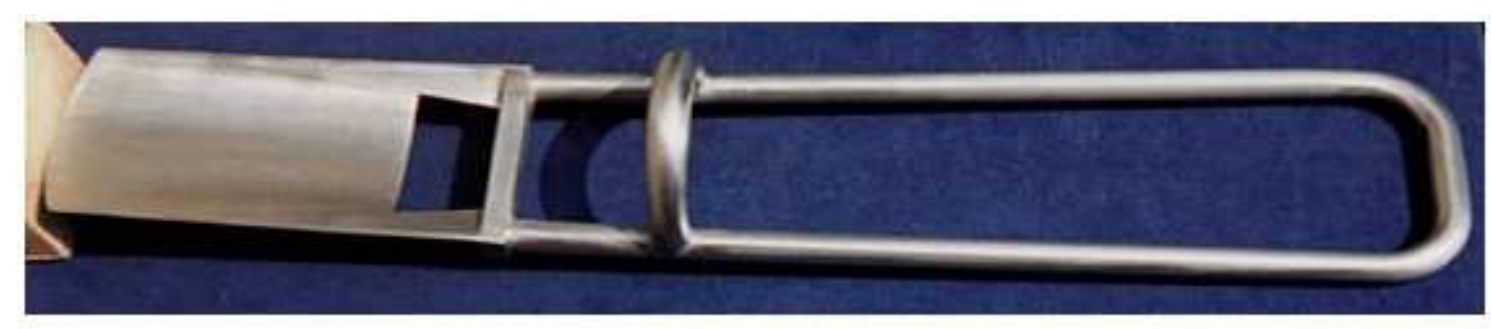

Fig. 1: An Appel Spade used for Gardening [11]

The Appel Spade was designed in such a way that it utilises the strength of the tool and the strength of the body in an efficient manner. Made of stainless steel that negates rusting and welded into a single, solid tool, the 3.6 kilogram spade itself is relatively indestructible [12]. This helps save the maintenance costs as this spade does not rust and on top of that, the durability of this spade even allows it to be passed down to several generations [12].

In short, the Appel Spade has good durability, good design, low maintenance cost and is most importantly, user friendly [12].

Kitchen Apparatus. For this section, the second review in this paper will be done on a specific kitchen tool known as the Eggcurate Digital Kitchen Scale. As the world's first 3-in-1 kitchen appliance, this scale not only features the ability to weigh up to 2 kilograms in weight, it also features an accuracy resolution of 1 gram [13]. It also has the option to weigh in ounces as well. On top of that, this kitchen scale comes in a small form factor that allows it to fit in kitchens that lack space [13].

As shown in Figure 2, the three main human-machine interfaces that this kitchen scale features are the weigh zone, four main buttons, as well as a LCD display screen. The weigh zone, as the name implies, is the area and location to put the intended items to be weighed. The scale comes with two plates, one which is flat and another which is concaved [13]. The need to change plates would be undesirable in an ergonomist's point of view as it requires extra work to be done [13]. This can be very energy consuming for the ageing population. The multi-functional buttons around the display screen however, can be considered ergonomic in the sense that they are large enough to accommodate large-sized hands and provide excellent feedback when pushed [13]. The LCD display screen is also at an adequate and appropriate size which makes it easier for the user to read from [13]. 


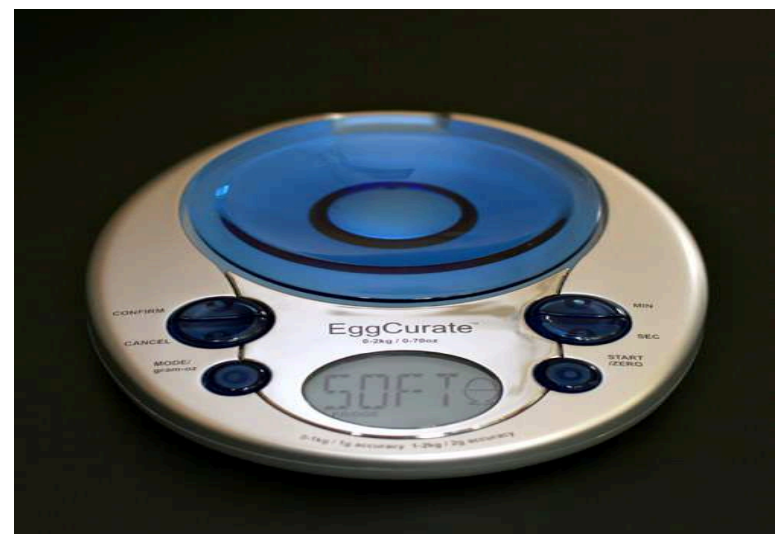

Fig. 2: Eggcurate Digital Kitchen Scale [13]

The comfort and efficiency factor of this kitchen scale comes in the form of accuracy and precision [13]. With a built-in timer and $80 \mathrm{dBA}$ alarm, users do not need to worry about overcooking or undercooking issues as the alarm is usually loud enough to notify the user of the completion of the boiling process [13].

To conclude, this kitchen scale is indeed an ergonomic product, not only for the ageing population, but also for other professionals like chefs and bakers or even egg aficionados [13].

Table 1: Summary of the Ergonomics Aspects of the Appel Spade and Eggcurate Kitchen

\begin{tabular}{|l|c|l|c|}
\multicolumn{2}{|c|}{ Appel Spade } & \multicolumn{2}{c|}{ Eggcurate Kitchen Scale } \\
\hline Ergonomic Aspects & Authors & Ergonomic Aspects & Authors \\
\hline Stainless Steel & Appel [11] & Small form factor & Adams [13] \\
\hline Two vertical handles in an inverted U-shape & Appel [11] & Multi-function buttons & Adams [13] \\
\hline Efficient strength utilisation & Adams [12] & Adequate LCD display screen size & Adams [13] \\
\hline
\end{tabular}

\section{Relevance to the ageing population}

The ergonomics aspects that have been briefly identified in this review can be useful for engineers in order for them to innovate and improve the designs of various conventional tools and apparatus. This review serves as a reference for not only for these engineers but also for ergonomics researchers that study the usability of these tools and apparatus for the ageing population, with hope that they can be provided with useful ergonomics information regarding these ergonomic garden tools and kitchen apparatus.

\section{Conclusion}

Generally, this review provides a summary on the ergonomics aspects of the garden spade and the digital kitchen scale. The ageing population is constantly growing and the engineers of these tools and apparatus should take the limitations of the ageing population into account during the design process. Ergonomics considerations such as comfort and usability in regards to the ageing population should be further emphasised since the ageing population would be more vulnerable to common injuries while using these tools and apparatus.

\section{References}

[1] S. Tribess, Jair Sinda Virtuoso Junior, and R. J. d. Oliveira, Physical Activity as a Predictor of Absence of Frailty in the Elderly, 58 (2012) 341-347.

[2] Information on http://www.clhio.ca/how-affordable-tools-and-technology-will-help-ourageing-population-stay-independent-longer/.

[3] R. Q. Barros, M. M. Soares, and M. G. Fernandes, Ergonomic Evaluation of Manual Force Levels of the Elderly in the Handling of Products: An Analysis Using Virtual Reality, (2014). 
[4] R. Kumar, "Ergonomic Evaluation and Design of Tools in Cleaning Operation," Doctoral Thesis, Department of Human Work Sciences, Luleå University of Technology, 2006.

[5] J. L. Fozard, J. A. M. Graafmans, J. Rietsema, H. Bouma, and A. v. Berlo, "Aging and Ergonomics: The Challenges of Individual Differences and Environmental Change," in Human Factors and Ergonomics Society Europe Chapter Annual Meeting, Soesterberg, The Netherlands, 1993.

[6] T. Phiriyapokanon, "Is a Big Button Interface Enough for Elderly Users? Towards User Interface Guidelines for Elderly Users," Master Thesis, Computer Engineering Department, Mälardalen University, Sweden, 2011.

[7] D. J. McConnell, The Forest Farms of Kandy: And Other Gardens of Complete Design, Ashgate, 2003.

[8] Information on http://inventors.about.com/od/kstartinventions/a/kitchen.htm.

[9] Information on http://ergonomics.about.com/od/lawngarden/tp/yardroold.htm.

[10] Y. C. Jiang, "Ergonomic Improvement on the Farm/Garden Hoe," Bachelor of Science Dissertation, California Polytechnic State University, San Luis Obispo, 2011.

[11] Information on http://www.abledata.com/abledata.cfm?pageid=113582\&orgid=186414.

[12] Information on http://ergonomics.about.com/od/gardeningequipment/fr/appel_spade.htm.

[13] Information on http://ergonomics.about.com/od/buyingguide/fr/eggcurate.htm. 